\title{
EL HOMBRE, SUS VIAJES Y LA SALUD
}

\author{
AGUSTÍN IZA STOLL
}

Universidad Norbert Wiener

\section{INTRODUCCIÓN}

La relación del hombre con sus viajes y la salud viene de tiempos inmemoriales. Desde el nomadismo el hombre se desplazó buscando hogar, alimentación y bienestar; y al caminar por diversos territorios sufrió las inclemencias del tiempo; hubo hambre y necesidades que afectaron su salud. La relación entre viaje y salud, que se inició con la humanidad, continúa en el presente; aumenta progresivamente y se prolongará indefinidamente. George Mikes, un escritor irónico húngaro dijo lo siguiente: "Viajar es el nombre de una enfermedad moderna que quedó fuera de control a mitad de los años cincuenta y se sigue expandiendo. La enfermedad cuyo nombre científico es Travelitis Furiosus se transmite por la prosperidad." Y efectivamente, en la medida en que el mundo ha ido mejorando económicamente (más en algunas regiones que en otras), los viajes son más frecuentes, menos costosos, más extensos y se pueden hacer por tierra, mar y aire.

La salud y el turismo inciden en la economía de los países. La salud incentiva el desarrollo económico y permite una población apta para el trabajo; el turismo, que crece con gran velocidad en los últimos quinquenios, se ha convertido en un factor importante en el Producto Bruto Interno de muchos países.

\section{HISTORIA}

El conocimiento de la medicina occidental de la Antigüedad nos ha llegado a través de Homero, Hipócrates, Plinio y Herodoto. Este último, contemporáneo de Hipócrates, escribió nueve libros que relataban sus viajes, y a quien Cicerón llamó el padre de la Historia. Herodoto nació en Halicarnaso, en el Asia Menor, una ciudad dominada por los persas. Debido a su oposición al régimen fue exiliado a Samos y desde allí inició viajes por Grecia, Babilonia, Fenicia, Egipto y Asia Menor, en los que obtuvo muchos conocimientos sobre la vida en las ciudades y el cuidado de la salud, y de los accidentes y heridas sufridas en las guerras. Dejó de lado la concepción mágico-religiosa de la enfermedad, siguiendo los conceptos hipocráticos, y difundió la relación importante de la naturaleza con la salud y la enfermedad. Escuchando las versiones orales de los ciudadanos de las diferentes ciudades, y analizándolas críticamente, escribió en prosa sus hallazgos.

Romero, Huesca y colaboradores explican cómo Herodoto realizó una descripción de la medicina egipcia, con énfasis en las técnicas de embalsamamiento, la especialización de médicos en áreas del cuerpo humano o de enfermedades, los problemas médicos comunes y procedimientos quirúrgicos, como la circunci- 
sión, la castración o la enucleación ocular; asimismo, describió las heridas traumáticas producidas durante las guerras, su diagnóstico y tratamiento ${ }^{1}$. Galeno también emprendió viajes para enterarse del manejo de los problemas médicos en otras ciudades, como en Éfeso, donde encontró métodos para aliviar enfermedades físicas y mentales.

Marco Polo conoció enfermedades en sus viajes a China; Darwin encontró la enfermedad de Chagas; Magallanes vio cómo morían sus tripulantes con escorbuto; él mismo pereció en Filipinas. Se especula mucho sobre si los viajes de Colón a las Américas trajeron la viruela, la que diezmó a las poblaciones nativas. La peste, difundida por viajeros, produjo la muerte de numerosos europeos que huían alejándose de la enfermedad y de la muerte.

En el contexto peruano, los que iban a trabajar al Callejón de Huaylas, en Ancash, se encontraron con pacientes que tenían verrugas y morían con anemia severa. Daniel A. Carrión, investigador peruano, un estudiante de medicina, se inoculó el contenido de una verruga y contrajo la anemia, que lo llevó a la muerte: al inmolarse descubrió que la verruga y la anemia eran parte de una sola enfermedad. En su honor se llama entonces la Enfermedad de Carrión.

\section{OCIO}

El ocio ha merecido mucha atención en los últimos tiempos, pero su interpretación ha ido variando con el tiempo. Los griegos consideraban que el término skholé expresaba abstenerse de las actividades cotidianas. Era patrimonio de las clases privilegiadas que podían destinar tiempo a actividades intelectuales, de reflexión filosófica y de meditación, y que les permitía alcanzar las virtudes. En cambio los romanos, con su vocablo otium, se referían al descanso y a la diversión; era un término opuesto al de negotium, que significa trabajo (negocio y comercio). Se desprende que en la cultura occidental antigua la actividad del otium era más importante que la del negotium ${ }^{2}$. Luego, según Dumazedier, en el siglo XX surge el ocio como resultado de la revolución industrial, etapa en la que se instituyen las horas de trabajo al día, las vacaciones y la jubilación, lo que permite a los trabajadores tener espacios libres y la posibilidad de viajar ${ }^{3}$.

\section{TURISMO DE SALUD}

El turismo es el desplazamiento temporal de personas desde su lugar de origen y la consiguiente recepción de estas, visitantes, por anfitriones. Se sustenta en la disposición del patrimonio turístico de la zona o región o país que se visita, y que incluye recursos naturales (mar, ríos, montańas, etc.) y culturales (fiestas, gastronomía, arte popular, monumentos, tradiciones, etc.). En su visita, el turista se encuentra con un ambiente y costumbres diferentes, que debe respetar, pero donde también puede ver comprometida su salud, por diversos agentes: temperatura, comida, relaciones sexuales no protegi-

\footnotetext{
${ }^{1}$ Andrés Romero-y Huesca, Julio Ramírez-Bollas, Sergio López-García, Carlos Valenzuela-Salazar, Francisco Javier Ponce-Landín. Contribuciones de Herodoto a la cirugía en el análisis historiográfico de sus Historias. Cir Ciruj 2004; 72: 525-532.

${ }^{2}$ Christianne L. Gomes y Rodrigo Elizalde. Horizontes latinoamericanos del ocio. Editorial Universidade Federal de Minas Gerais (UFMG), Belo Horizonte, Brasil, 2012.

${ }^{3}$ Joffre Dumazedier. Lazer e cultura popular. Sao Paulo. Perspectiva, 1976.
} 
das, drogas, accidentes, etc. Dos temas son importantes en esta área: la salud del turista y el turismo por razones de salud o también llamado turismo médico.

\section{LA SALUD DEL TURISTA}

Diversas organizaciones nacionales e internacionales han publicado una serie de recomendaciones para los viajeros, que incluyen edad, sexo, condición de los visitantes, país de destino, problemas médicos con los que se viaja -alergias, inmunodeficiencias, enfermedades, medicamentos, gestación, lactancia materna-, discapacidades físicas y mentales, entre otras ${ }^{4}$.

Se recomienda tener una consulta médica, de preferencia con un especialista, que realice una evaluación completa y proporcione recomendaciones generales y vacunación de ser necesaria. Estas recomendaciones generales también son proporcionadas por agentes de turismo y por las entidades oficiales del país que se visita, que no se limitan solamente a visas, $y$ es importante seguirlas para disfrutar del viaje. Un test desarrollado por el Massachusetts General Hospital y el Center for Diseases Control (CDC) de Atlanta, en Estados Unidos, que está referido a viajeros estadounidenses, es útil también para cualquier turista: se denomina Global TravEpiNet, y se encuentra en el siguiente enlace: <https:/gten.travel/prep/prep>.

Las patologías más frecuentes en los viajeros de aventura se ilustran en la siguiente tabla, que fue publicada en la Revista The Lancet en 2017:

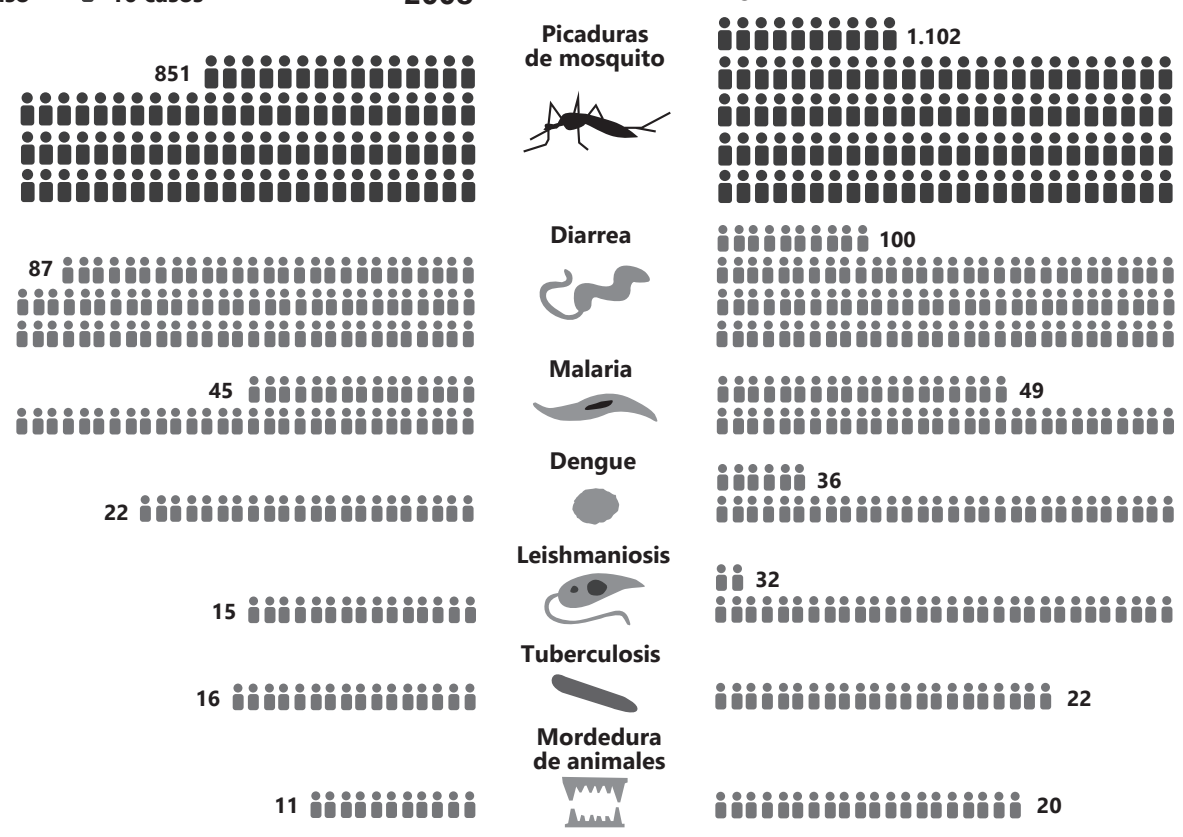

\footnotetext{
${ }^{4}<$ http://www.cdc.gov/features/medicaltourism/index.html>.
} $<$ http://www.eden.org.mx/esp/turismo7turismoindex.htm>. 


\section{TURISMO MÉDICO}

Se refiere a personas que se desplazan de un país a otro para recibir un tratamiento médico. Los más frecuentes son turismo dental, turismo quirúrgico, turismo estético o cosmético (cirugía plástica o regenerativa) $)^{5}$.
Se denomina Turismo Wellness o Turismo de Bienestar a aquel cuyo propósito de viaje es la promoción de la salud a través de actividades físicas, hidroterapia, o enfoques psicológicos o espirituales, un turismo en franco crecimiento en el mundo, como puede apreciarse en la siguiente tabla:

\section{Previsiones de llegadas de turistas de bienestar}

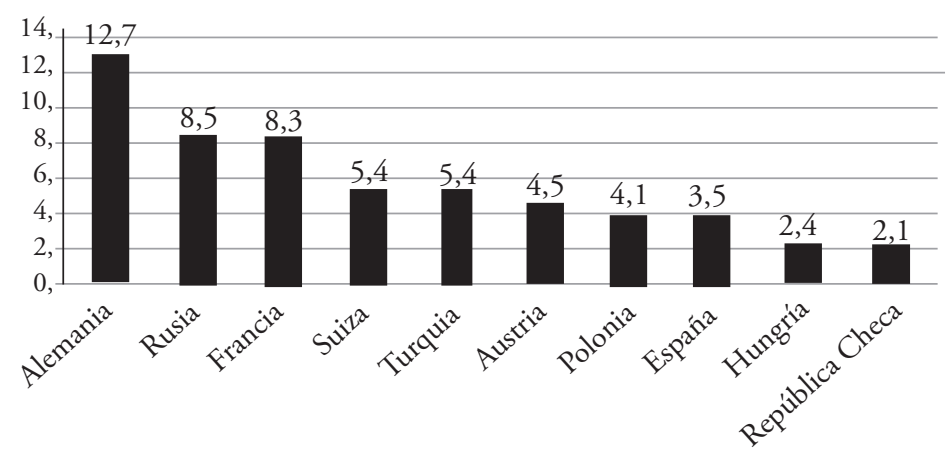

Fuente: Elaborado a partir de ITB Berlin (n.d.) Wellness tourism added arrivals forecast in Europe from 2013 to 2017, by contry. En Statista - The Statistics Portal. Consultado el 21 de marzo de 2017.

El Top 30 de destinos de turismo médico está liderado por Canadá, seguido por Reino Unido e Israel según el denominado Índice de Turismo de Salud desarrollado por Fetscherin \& Stephano y recogido por Ostelea School of Tourism \& Hospitality. En cuanto a la búsqueda de tratamientos médicos, los países más visitados se encuentran en la tabla que se observa en la siguiente página.

Cada vez más personas tienen interés por el turismo de salud, si bien la edad exige necesidades diferenciadas. El perfil senior busca tratamientos que ayuden a las personas a mantenerse en forma, al tiempo que acceder a una oferta complementaria conformada por experiencias con un alto componente de actividad física y de aventura. Los millennial optan por terapias alternativas, tratamientos cosméticos y de bienestar físico y mental, así como por una oferta complementaria que incluya inmersión en la comunidad, la cultura, el idioma y las tradiciones locales.

Según Centers for Disease Control and Prevention (CDC), turismo médico se refiere a viajar a otro país para recibir atención médica. Muchos factores influyen en la decisión de buscar atención médica en el extranjero. Algunas personas viajan para recibir atención porque el tratamiento es más barato. Otros turistas médicos pueden ser inmigrantes que prefieren regresar a su país de nacimiento

\footnotetext{
${ }^{5}$ American College of Surgeons. Statement on medical and surgical tourism. Enlace: <www.facs.org/fellows_info/ statements/st-65.html>. European Commission. Cross-border care policy: <http://ec.europa.eu/health/cross_ border_care/policy/index_en.htm>.
} 


\begin{tabular}{|c|c|c|}
\hline Posición & Destinos & $\begin{array}{c}\text { Índice de Turismo } \\
\text { Médico }\end{array}$ \\
\hline 1 & Canadá & 76.9 \\
\hline 2 & Reino Unido & 74.8 \\
\hline 3 & Israel & 74.2 \\
\hline 4 & Singapur & 74.0 \\
\hline 5 & Abu Dabi & 73.0 \\
\hline 6 & Costa Rica & 72.8 \\
\hline 7 & Italia & 72.0 \\
\hline 8 & Jordania & 71.1 \\
\hline 9 & Alemania & 70.7 \\
\hline 10 & Filipinas & 70.7 \\
\hline 11 & Japón & 70.4 \\
\hline 12 & Francia & 70.2 \\
\hline 13 & Corea del Sur & 70.0 \\
\hline 14 & Taiwán & 69.4 \\
\hline 15 & España & 69.3 \\
\hline 16 & Brasil & 67.9 \\
\hline 17 & Jamaica & 67.7 \\
\hline 18 & India & 67.5 \\
\hline 19 & Colombia & 67.4 \\
\hline 20 & Panamá & 67.0 \\
\hline 21 & Dubái & 66.1 \\
\hline 22 & Rep. Dominicana & 66.0 \\
\hline 23 & Polonia & 65.5 \\
\hline 24 & Tailandia & 65.5 \\
\hline 25 & Argentina & 64.4 \\
\hline 26 & China & 63.1 \\
\hline 27 & Sudáfrica & 62.1 \\
\hline 28 & México & 61.0 \\
\hline 29 & Turquía & 61.0 \\
\hline 30 & Rusia & 50.3 \\
\hline
\end{tabular}

para recibir atención médica. Otros pueden viajar para recibir un procedimiento o terapia no disponible en el país en que viven. Los procedimientos más comunes a los que las personas se someten en viajes de turismo médico incluyen cirugía estética, odontología y cirugía cardíaca.

Sin embargo, el turismo médico puede ser causa de problemas durante los procedimientos o al regresar al país. Por estas consideraciones muchas instituciones han publicado una serie de recomendaciones a los viajeros, que incluyen con- seguir información sobre la calidad y experticia del profesional y acreditación del hospital donde se realizará la atención médica, facilidades para el pre y posoperatorio, llevar su historia médica y traer un informe médico del especialista o centro donde se realizó la atención.

Asimismo, se recomienda viajar unos días o semanas antes de la intervención y no viajar en avión de regreso al país, sino al menos una semana después de la operación, por la posibilidad de que se presenten coágulos y embolia pulmonar ${ }^{6}$.

\footnotetext{
${ }^{6}$ Aerospace Medical Association guidelines for airline travel provide useful information on the risks of travel with certain medical conditions. Enlace: <www.asma.org/asma/media/asma/Travel-Publications/paxguidelines.pdf >.
} 


\section{TURISMO DE TRASPLANTE}

Una de las formas más nuevas y controvertidas de turismo médico es el "turismo de trasplante", que es un viaje con el fin de recibir un órgano o células madre, comprados a un donante no relacionado para el trasplante, o recibir otro biomaterial (célula, tejido). Además, varios estudios de turismo médico identificaron problemas potenciales (uso inadecuado de medicamentos, infecciones y otros) que los viajeros y los clínicos deben tener en cuenta al considerar el trasplante en el extranjero. La Asamblea Mundial de la Salud alentó a los países miembros a tomar medidas con arreglo a la protección de los segmentos más pobres o vulnerables del turismo de trasplante, que son los donantes. Estas directrices enfatizan que las células, los tejidos y los órganos solo deben donarse libremente, sin ninguna forma de incentivo financiero ${ }^{7}$.

\section{PROBLEMAS DE SALUD Y CON- DUCTAS DE LOS VIAJEROS}

El número de turistas internacionales ha excedido el número de mil millones en los últimos ańos; pero existen pocos estudios prospectivos que hayan estudiado los factores de riesgo, las enfermedades y las conductas de los viajeros. Un estudio finlandés reciente evaluó este problema, reclutando a turistas antes de que viajaran, y por un periodo de hasta tres semanas después de su regreso: más de 500 viajeros, a los que se sometió a una encuesta antes y después del viaje, que incluía edad, sexo, destino, duración y propósito del viaje, conducta de riesgo y enfermedades. Un hallazgo central de este trabajo es una alta tasa de morbilidad. A pesar de las eficientes medidas profilácticas tomadas antes del viaje, el $76 \%$ de las personas reportaron enfermedad mientras estaban fuera del país; el $25 \%$ todavía tenía síntomas dos días después de regresar. Con respecto a la morbilidad en diferentes regiones geográficas, fue significativamente menor en los viajeros a países de economía desarrollada $(20 \%)$ que aquellos que visitaron países en vía de desarrollo (80 \%). Los viajeros que se desplazaron a Asia (sur y este), África (sur), fueron los que tuvieron mayores problemas de salud (diarrea del viajero). Este estudio concluye que de los viajeros que visitan las regiones subtropicales, a pesar de medidas preventivas tan eficientes como las vacunas, profilaxis de la malaria y los consejos médicos, la mayoría enfermó durante o después del viaje. La diarrea del viajero fue la enfermedad más común, seguida por problemas dérmicos y fiebre durante el viaje. Después del viaje los problemas más frecuentes fueron fiebre, infecciones del tracto respiratorio y problemas de la piel. Los síntomas generalmente fueron leves y no requirieron cuidado médico; pero es importante constatar que un tercio de los viajeros (provenientes de un país desarrollado y que se sometieron a un control médico antes del viaje), tuvieron problemas de salud después de regresar del viaje. Concluyen estos investigadores que es muy importante insistir con los consejos médicos antes de viajar.

\section{MIGRACIÓN}

Lo que hemos referido hasta aquí es el desplazamiento voluntario de personas

7 World Health Organization. Guiding principles on human cell, tissue and organ transplantation. Enlace: <www. who.int/transplantation/Guiding_PrinciplesTransplantation_WHA63.22en.pdf>. 
que por diversas razones viajan a otros lugares. Pero existen poblaciones que por razones económicas, sociales o políticas se ven obligadas a dejar su hábitat y buscar lugares que les proporcionen bienestar personal y familiar. Las migraciones de africanos a Europa y las de latinoamericanos hacia otros países o ciudades americanos, han sido en estos tiempos motivo de preocupación por la enorme cantidad de familias, personas solas, madres con hijos pequeños, que recorren grandes distancias en búsqueda de una vida mejor. Pero estas poblaciones migrantes traen consigo problemas de salud; son recibidas por otros países, pero también se encuentran con la oposición de parte de los pobladores que piensan que traen enfermedades y que les quitan puestos de trabajo. Asimismo, los países receptores deben emplear presupuesto para acomodar a los recién llegados.

Los problemas sanitarios más frecuentes en los migrantes africanos que llegan a Europa son accidentes, hipotermia, quemaduras, enfermedades gastrointestinales, embarazos, diabetes, etc., y los niños padecen desnutrición, deshidratación, problemas gastrointestinales y respiratorios; tienen condiciones subóptimas de salud y están expuestos a otras enfermedades.

Los migrantes sudamericanos tienen desórdenes psicosociales, abusos de droga, alcoholismo, violencia, trata de personas, prostitución, prácticas sexuales sin protección, VIH, mortalidad neonatal, y otras que empeoran las enfermedades crónicas degenerativas, como hiperten- sión arterial o diabetes. Entre 2014 y 2015, el país sudamericano que dio más visas fue el Perú: el $28 \%$ del total de visas, seguido por Colombia y Bolivia.

Ha existido mucha preocupación sobre cómo manejar los problemas de salud en la población migrante. La Organización Mundial de la Salud recomienda que no se hagan descartes obligatorios de enfermedad a esta población porque lo que se consigue es contraproducente; se sugiere exámenes médicos voluntarios y vacunaciones de ser necesarias ${ }^{8}$.

Debe insistirse en el tema de que no son los migrantes necesariamente quienes traen las enfermedades. Puede revisarse el caso del Ébola. Este comenzó en el África, en tres países, donde no había más de 30 o 40 pacientes. La Ministra de Género de Liberia, uno de los países comprometidos en este tema, dijo lo siguiente: «Nosotros hemos estado en guerra, sabemos por dónde vienen las balas, pero no sabemos por dónde viene el Ébola»; y lo que se practicó fue lo pertinente: reportar rápidamente y tomar medidas preventivas en el mundo, especialmente en los puertos y aeropuertos; y esas recomendaciones impidieron una epidemia masiva de Ébola.

El Ébola llegó a España a través de dos misioneros febriles que trabajaban en el África; fueron atendidos en un hospital con las condiciones adecuadas para estos pacientes: aislados. Estos dos misioneros desagraciadamente fallecieron; una técnica en enfermería se contagió porque a pesar de que usó un uniforme especial,

\footnotetext{
${ }^{8}$ Organización Mundial de la Salud. Consejo Ejecutivo. EB122/11. 122a Reunión 20 de diciembre de 2007. OMS. Grupo Mundial sobre la Migración. Enlace: <https:/www.who.int/un-collaboration/partners/mechanisms-global-migration/es/>. United Nations. Trends in international migration, 2015 [Internet]. New York: Department of Economic and Social Affairs, UN; 2015.
} 
guantes, gorras y botas, se infectó muy probablemente cuando se cambió la vestimenta; pero felizmente sobrevivió ${ }^{9}$. No se han reportado después pacientes con Ébola en España, ratificándose que los migrantes no necesariamente traen con ellos la enfermedad.

\section{VIAJES ESPACIALES TRIPULADOS}

Desde hace ya decenas de años los seres humanos han visto la posibilidad de viajar y explorar otros mundos, diferentes del nuestro; la ciencia y la tecnología han ido solucionando los problemas; y ya se permite la vida en el espacio. Por eso ha habido y sigue habiendo una serie de estudios fisiológicos de la vida en situaciones de microgravedad. Los viajes espaciales introducen la necesidad de un soporte vital, es decir, mantener un ambiente interior en la cápsula que permita defenderse del vacío exterior y de sus temperaturas extremas. Este sistema de soporte vital logra controlar el ambiente, la presión atmosférica, el suministro de agua, la gestión de residuos y la detección y extinción del fuego. La permanencia de personas en el espacio exterior presenta dos problemas principales: la radiación cósmica y la ausencia de gravedad.

Los rayos cósmicos pueden ocasionar desarrollo de cataratas y tumores; en consecuencia, las naves espaciales deben tener escudos físicos, electromagnéticos y estereostáticos que eviten que el astronauta reciba radiación mayor que desencadene en el futuro un cáncer mortal. En cuanto a la ausencia de gravedad, el viajero espacial puede desarrollar inicialmente náuseas, mareos o pérdida de apetito, que son transitorios. En un periodo más prolongado se produce la disminución de la masa muscular, que los astronautas tratan de compensar con ejercicio.

Los huesos sufren un proceso de desmineralización, que reduce la masa ósea del $1 \%$ al $2 \%$ cada mes, que vuelca al torrente sanguíneo sales como el fosfato de calcio, el que puede formar cálculos renales. Asimismo, la columna vertebral se estira y puede aumentar unos centímetros al viajero. Cuando disminuye la atracción de la tierra, los líquidos corporales se dirigen hacia la cabeza, que se hincha, y puede producir cefaleas. Las extremidades inferiores pierden volumen y la falta de gravedad produce atrofia en los músculos. Los cuerpos flotan en la cápsula espacial y se alteran la percepción, la aceleración y el equilibrio, por disminución de la función de los otolitos, y entonces la posición del cuerpo debe ser registrada por la visión y no por los órganos del equilibrio.

La NASA ha encontrado que el corazón de los astronautas sometidos a la ingravidez en el espacio se había vuelto más o menos $10 \%$ más esférico, debido a la pérdida de masa muscular. La tensión, la nutrición deficiente y la falta de sueño originan una disminución del sistema inmunológico. El $29 \%$ de los astronautas que estuvieron dos semanas en el espacio desarrollaron problemas de visión, y hasta el $60 \%$ de los que permanecieron en la estación espacial internacional por varios meses, probablemente debido a un aplanamiento de los globos oculares. El aspecto psicológico es también importante en los viajes largos, por lo que es

\footnotetext{
${ }_{9}$ OMS Enfermedad por el virus del Ébola. Enlace: <https://www.who.int/es/news-room/fact-sheets/detail/ebola-vi-
} rus-disease>. 
indispensable una adecuada selección y preparación de la tripulación ${ }^{10}$.

Los estudios realizados en los astronautas que regresan a la tierra han mostrado que estas modificaciones tornan a su condición normal en un tiempo relativamente corto de días o semanas.

\section{COROLARIO}

La condición humana es viajar -por exigencias económicas, oportunidades placenteras de conocer otras latitudes y adolescencia de limitaciones de salud. Estos aspectos en la historia se combinan de diversas formas (se emprenden viajes y se contraen enfermedades, se viaja para curarse, etc.); pero todas las alternativas siempre suponen la necesidad de viajar y la exigencia de servicios para ello; y la adolescencia de salud y la exigencia de servicios de salud. Así, siendo que la salud y los viajes -incluidos los turísticos- constituyen actividades económicas ingentes, estas en su confluencia se potencian y fortalecen entre sí, de modo que en una sociedad como la peruana, tanto el Estado como los privados tienen oportunidades de ofrecer salud y viajes para desarrollar su economía.

\footnotetext{
${ }^{10}$ NASA: HumanResearchProgram

<//www.nasa.gov/exploration/humanresearch/areas_study/physiology/index.html>.
} 